\title{
Quality of life in swallowing of the elderly patients affected by stroke
}

\author{
Émerson Soares PONTES ${ }^{1}$, Ana Karênina de Freitas Jordão do AMARAL², \\ Flávia Luiza Costa do RÊGO², Elma Heitmann Mares AZEVEDO ${ }^{3}$ and Priscila Oliveira Costa SILVA ${ }^{2}$
}

Received 21/6/2016 Accepted 12/9/2016

\begin{abstract}
Background - The elderly population faces many difficulties as a result of the aging process. Conceptualize and evaluate their life quality is a challenge, being hard to characterize the impact on daily activities and on functional capacity. The stroke is one of the most disabling neurological diseases, becoming a public health problem. As an aggravating result, there is dysphagia, a disorder that compromises the progression of the food from the mouth to the stomach, causing clinical complications to the individual. Objective - Characterize the life quality of the elderly swallowing affected by stroke. Methods - Cross-sectional study conducted at the University Hospital, attended by 35 elderly with stroke, being 19 women and 16 men, with age between 60 and 90 years old, that self-reported satisfactory overall clinical picture. It was applied the Quality of Life Swallowing protocol. The data were statistically analyzed, by means of ANOVA tests, Spearman correlation, $t$ test, with significance level of $5 \%$. Results - The mean age was 69.5 years; as for the scores obtained by the 35 participants in the 11 domains of the protocol, it was observed a change in score indicating severe to moderate impact in quality of life related to self-reported swallowing (31.8\% to 59.5\%); the domain that most interfered was the feeding time ( $31.8 \%)$.

Conclusion - Elderly affected by stroke that present dysphagia has low scores in quality of life related to swallowing.
\end{abstract}

HEADINGS - Stroke. Deglutition disorders. Health of the elderly. Quality of life.

\section{INTRODUCTION}

Conceptualize the quality of life is subjective, multidimensional, influenced by several aspects related to education, economic and socio-cultural aspects, such as the personal satisfaction of the individual in relation to life expectancy, health perception, interests, physical, emotional and socioeconomic aspects ${ }^{(5,21)}$.

The rising expectations of the population and the high rate of prevalence of neurodegenerative diseases amplify the interest in studies on quality of life in elderly ${ }^{(2)}$. The elderly population faces many difficulties as a result of the aging process and therefore conceptualize and evaluate their quality of life is a challenge because it is difficult to characterize the impact that senescence causes on their daily activities and on their functional capacity ${ }^{(4,5,24)}$.

Senescence refers to a stage of life in which there is a series of biological, physiological and psychological changes, but these changes must be regarded as natural and typical of this phase of life ${ }^{(7,9)}$. Some of the morphological and physiological changes caused by advancing age are changes in orofacial motor skills (M.O), voice, hearing and language. In M.O, stomatognathic functions generally tend to become slower, with features that reflect losses in orofacial structures that occur with advancing age. Changes in chewing and in the swallowing process significantly impact in a negative way on the nutrition and quality of life of elderly ${ }^{(1,5,34)}$.

Swallowing is a complex act that requires the control and regulation at all levels of the nervous system, it is the act of transporting food from the mouth to the stomach effectively and safely. It can be divided into several stages with different anatomical and/or functional characteristics: oral preparation, oral, pharyngeal and esophageal; the aging process modifies the orofacial structures, because there may be loss of elasticity of the oral mucosa, less production of saliva, decreased motor function and mobility of lips, tongue, buccinator, larynx and pharynx, that is, all the involved muscles can be impaired resulting in losses in the execution of the movements necessary for safe and efficient swallowing ${ }^{(3,9,19)}$.

When any disorder in this sequential and complex process occurs, there is dysphagia regarding the difficulty of coordinating the movements of chewing, swallowing and breathing. It is caused by changes in one or more stages of swallowing and may be caused by neurological and/or structural causes ${ }^{(28)}$.

The elderly stroke can present with regard to dysphagia, alterations in the oral phase of swallowing such as: previous leakage of saliva and/or food, difficulty in chewing, increased oral preparation time, inefficiency in the preparation and/or transit of the bolus with subsequent leakage and accumulation of food in the lip or oral groove, inability to push the bolus into the pharynx. In the pharyngeal phase of swallowing, the most common symptoms are: delay in triggering the pharyngeal swallowing, reduced hyolaryngeal elevation, laryngeal penetration, aspiration, stasis in valecule, in piriform sinuses and in pharyn $\mathrm{x}^{(26,27)}$.

The stroke is a brain-vascular disease and is the major cause of deaths among people over 60 years and the second between 15-59 years. In Brazil, despite the reduction in mortality rates, it is still the main cause of death ${ }^{(15,16)}$. It may be ischemic ( $80 \%$ of cases) which constitutes occlusion of a blood vessel, interrupting blood flow to specific regions of the brain and resulting in losses of the neurological functions dependents on the affected region, or may be hemorrhagic (about 20\% case) ${ }^{(27)}$.

Declared conflict of interest of all authors: none

Disclosure of funding: no funding received

'Universidade Federal da Paraíba, João Pessoa, PB, Brasil; ${ }^{2}$ Departamento de Fonoaudiologia, Universidade Federal da Paraíba, João Pessoa, PB, Brasil; ${ }^{3}$ Departamento de Fonoaudiologia, Universidade Federal do Espírito Santo, Vitória, ES, Brasil.

Correspondence: Émerson Soares Pontes. Rua: João Gomes da Silva, 71. Centro - CEP: 58307120 - Bayeux, PB, Brasil. E-mail: emerson-soares21@hotmail.com 
The aging correlation with stroke is justified, because the age is a primary risk factor for the disease. As an aggravating result there is dysphagia which may affect the progression of food from the mouth to the stomach, resulting in clinical implications of different degrees to the patient. Such a change may compromise all the swallowing process in relation to the phases and events of this function ${ }^{(12,25)}$.

Individuals affected by stroke involving the cerebral hemispheres and brain stem have dysphagia, with an incidence of $30 \%-80 \%$. The biggest changes are in the oral and pharyngeal phases of swallowing and are related to a high prevalence of morbidity and mortality because they cause nutritional changes, bronchial-tracheal saliva, secretions or food suction that may cause clinical complications such as dehydration, malnutrition and risk of aspiration and repetitive pneumonia ${ }^{(8,12,22)}$.

Describing the quality of life in a healthy elderly is a challenge facing the many variations that senescence can cause; when the elderly has a neurological disease, it becomes a greater challenge, but it is very important for monitoring the effectiveness of treatment as also to direct the management of these patients for appropriate action.

Cassol et al. ${ }^{(5)}$ aimed to know the perception of 104 healthy elderly forward to possible difficulties in swallowing and applied the Quality Protocol of Life Swallowing (SWAL-QOL) concluding that healthy elderly generally don't self-report significant changes to the quality life in swallowing, was observed that most of them had next maximum score of 100 points, indicating minimal interference self-reported by elderly. The domain that obtained the highest score was the "social" and with a lower average score was the feeding time ${ }^{(5)}$. In contrast another study evaluated the impact of dysphagia in the quality of life in individuals with Parkinson's disease and the results revealed that the elderly showed symptoms of dysphagia and with the progression of the disease, impacts on quality of life worsen in the areas: desire to feed, food selection and feeding time ${ }^{(18)}$ strengthening the presence of an underlying disease, it is a major aggravating factor for a worse quality of life related to swallowing elderly.

Studies about the elderly quality of life in relation to swallowing are not many yet, so this study aimed to characterize the quality of life in swallowing older adults diagnosed with stroke.

\section{METHODS}

This is an observational, descriptive and cross-sectional study with completion of undergraduate degree. Participated 35 elderly composing a convenience sample considering that they were awaiting neurological medical care in waiting room during a period of two months, and collection was held once a week for a single researcher, who had no previous contact with the participants.

As eligibility criteria, volunteers should be aged 60 years, of both sexes, having suffered any type of stroke, but with satisfactory overall clinical picture. It was adopted as exclusion criteria: older adults with psychiatric abnormalities, cancer, Chagas disease or other neurological diseases and have passed or be in speech-language therapy and/or physical therapy due to swallowing problem.

The elderly were approached for data collecting before their doctor's appointment. The average time for completing SWALQOL questionnaire ranged from 5 to 10 minutes and the application of the Protocol took place individually with each subject. The questions were read to the elderly, who reported one of the answer choices and had such an option indicated by the researcher.

The Quality of Life Swallowing Disorders - SWAL-QOL questionnaire, developed in the United States, in Brazil has been translated and validated in 2009 as: Quality of life in Dysphagia. It is a questionnaire intended to measure specific symptoms to assess the severity of oropharyngeal dysphagia, but also to know the real impact of swallowing changes at feeding time (20,31,38). $^{2}$

This questionnaire consisted of 44 questions that assess eleven areas: swallowing as a burden, desire to feed, the feeding duration, frequency of symptoms, food selection, communication, fear of eating, mental health, social functioning, sleep and fatigue.

The voluntiers had an average of up to 1 year post-stroke and self-reported dysphagia oropharingeal symptoms as difficulties related to chewing, the beginning of the pharyngeal phase, nasal reflux, choking, coughing during feeding. All of them answered about how often each question of each domain occurs using a Likert scale from 1 to 5 points (always, often, sometimes, a little and never). Briefly, it is the summation ratings method, in which each item is equally weighted and summed in an overall score scale. This allowed each question to be linearly transformed to a metric of $0-100,100$ indicating the most favorable state, and zero, the less favorable. The scores represent the percentage of possible total between the score.

The method of Likert Scale states that each item correlates significantly with the scale and the represented hypothesis ${ }^{(18)}$. After converting, the values of each response within each domain are added together and divided by the number of the related domain questions $^{(21,31,38)}$.

For the interpretation of the results, it is considered the following classification: 0-49 severe impact, 50-70 moderate impact and 71-100 discrete impact or no impact on quality of life related to swallowing ${ }^{(5,31)}$.

The SWAL-QOL also features four additional questions, which refer to possible modification or the need for adjustments of the elderly during the process of feeding ${ }^{(31)}$. This research shows a self-assessment of quality of life, recommended by the literature for being a complex issue. Elderly people who self-report worse quality of life presents a higher risk of morbidity and mortality compared to elderly who self-report a good quality of life ${ }^{(11,13)}$.

The data relating to SWAL-QOL questionnaire were tabulated, the variables were selected based on the research objectives. Statistical analysis was performed by the ANOVA tests, Spearman correlation, $t$ test. The significance level was $0.05(5 \%)$.

This study was approved by the Research Ethics Committee of the University Hospital under number 1.016.004. All participants signed the Free Agreement and Informed Term (TCLE).

\section{RESULTS}

The sample consisted of 35 elderly, being 19 women (54.3\%). The average age was 69.5 years with a standard deviation of \pm 8.5 . As for the schooling degree, 14 subjects $(40 \%)$ had incomplete 1 st degree; Ten $(28.6 \%)$ were illiterate. (Table 1$)$.

TABLE 1. Distribution of subjects according to the independent variables.

\begin{tabular}{lcc}
\hline Investigated Variables & $\mathbf{n}$ & $\%$ \\
\hline Gender & 16 & $45.7 \%$ \\
$\quad$ Male & 19 & $54.3 \%$ \\
$\quad$ Female & 10 & 28.6 \\
Instrution degree & 4 & 11.4 \\
$\quad$ Illiterate & 14 & 40.0 \\
Complet 1st degree & 5 & 14.2 \\
Incomplet 1 st degree & 1 & 2.9 \\
Complet 2 nd degree & 1 & 2.9 \\
Incomplet 2 nd degree & 35 & 100.0 \\
$\quad$ Complet 3rd degree & & \\
Total & & \\
\hline
\end{tabular}

Source: Research data, 2015. 
In relation to the scores obtained by 35 seniors in the 11 areas of SWAL-QOL protocol, it is observed that there is a variation in the average score indicating severe to moderate impact in quality of life related to swallowing self-reported by the elderly (Table 2). The area with the highest average score was the "Frequency of symptoms" which also showed the lowest standard deviation, showing less variability in the responses. The score with the lowest is the domain "feeding time" and the "social" field has the highest standard deviation, indicating greater variability in the responses.

TABLE 2. Descriptive distribution of domains (mean, standard deviation, minimum and maximum)

\begin{tabular}{lcccc}
\hline Domain & Mean & $\begin{array}{c}\text { Standar } \\
\text { deviation }\end{array}$ & Minimum & Maximum \\
\hline $\begin{array}{l}\text { 1. Swallowing as a } \\
\text { burden }\end{array}$ & 45.7 & 32.4 & 0.0 & 100.0 \\
2. Desire to feed & 56.2 & 28.3 & 0.0 & 100.0 \\
3. Feeding time & 31.8 & 35.5 & 0.0 & 100.0 \\
4. Frequency of & 59.5 & 19.6 & 16.1 & 96.4 \\
$\quad$ symptons & 55.0 & 35.6 & 0.0 & 100.0 \\
5. Food selection & 53.6 & 33.9 & 0.0 & 100.0 \\
6. Communication & 42.7 & 26.8 & 0.0 & 87.5 \\
7. Fear to feed & 47.6 & 33.0 & 0.0 & 100.0 \\
8. Mental health & 58.3 & 38.1 & 0.0 & 100.0 \\
9. Social & 43.9 & 22.2 & 0.0 & 100.0 \\
10. Sleep & 45.7 & 26.6 & 0.0 & 100.0 \\
11. Fatigue & & & & \\
\hline
\end{tabular}

Source: Research data, 2015.

Regarding the comparison of average total scores on SWALQOL between genders, results show no significant difference in the average seen in the fields with respect to gender, men and women had similar average of scores (Table 3).

TABLE 3. Distribution of SWAL-QOL domains according to the variable "Gender"

\begin{tabular}{|c|c|c|c|c|}
\hline & Gender & Mean & SD & Value of $P$ \\
\hline \multirow{2}{*}{ 1. Swallowing as a burden } & Male & 46.9 & 31.4 & \multirow{2}{*}{0.848} \\
\hline & Female & 44.7 & 33.9 & \\
\hline \multirow{2}{*}{ 2. Desire to feed } & Male & 58.9 & 19.1 & \multirow{2}{*}{0.617} \\
\hline & Female & 53.9 & 34.6 & \\
\hline \multirow{2}{*}{ 3. Feeding time } & Male & 23.4 & 33.5 & \multirow{2}{*}{0.203} \\
\hline & Female & 38.8 & 36.5 & \\
\hline \multirow{2}{*}{ 4. Frequency of symptons } & Male & 52.8 & 21.3 & \multirow{2}{*}{0.068} \\
\hline & Female & 65.2 & 16.5 & \\
\hline \multirow{2}{*}{ 5. Food selection } & Male & 60.9 & 31.5 & \multirow{2}{*}{0.365} \\
\hline & Female & 50 & 38.8 & \\
\hline \multirow{2}{*}{ 6. Communication } & Male & 52.3 & 28.2 & \multirow{2}{*}{0.848} \\
\hline & Female & 54.6 & 38.9 & \\
\hline \multirow{2}{*}{ 7. Fear to feed } & Male & 35.9 & 26.5 & \multirow{2}{*}{0.176} \\
\hline & Female & 48.4 & 26.3 & \\
\hline \multirow{2}{*}{ 8. Mental health } & Male & 48.4 & 32.4 & \multirow{2}{*}{0.889} \\
\hline & Female & 46.8 & 34.3 & \\
\hline \multirow{2}{*}{ 9. Social } & Male & 60.6 & 38.6 & \multirow{2}{*}{0.744} \\
\hline & Female & 56.3 & 38.5 & \\
\hline \multirow{2}{*}{ 10. Sleep } & Male & 46.9 & 22.5 & \multirow{2}{*}{0.479} \\
\hline & Female & 41.5 & 22 & \\
\hline \multirow{2}{*}{ 11. Fatigue } & Male & 48.4 & 27.2 & \multirow{2}{*}{0.587} \\
\hline & Female & 43.4 & 26.5 & \\
\hline
\end{tabular}

Source: Research data. Teste $t$ for independent samples. *Significant as 0.05 . Subtitle: SD: standard deviation
The correlation between the scores in the 11 areas of SWALQOL protocol and age was performed, the results show that there is a relationship between the average age and the field "Selection of food", this relationship is expressed in a negative way, that is, the greater the age, the lower the score of these domains. It is noteworthy that despite being found statistical significance, the value was low (0.339), indicating a weak correlation. However, this does not invalidate the results, which can be interpreted as a tendency to be confirmed in larger samples (Table 4).

TABLE 4. Correlation between the SWAL-QOL domains mean and the variable "Age"

\begin{tabular}{lcc}
\hline Domain & Correlation & $\boldsymbol{P}$-value \\
\hline 1. Swallowing as a burden & -0.286 & 0.096 \\
2. Desire to feed & 0.016 & 0.928 \\
3. Feeding time & -0.064 & 0.717 \\
4. Frequency of symptons & -0.129 & 0.461 \\
5. Food selection & -0.339 & $0.046^{*}$ \\
6. Communication & -0.104 & 0.553 \\
7. Fear to feed & -0.212 & 0.221 \\
8. Mental health & -0.056 & 0.748 \\
9. Social & -0.224 & 0.195 \\
10. Sleep & 0.003 & 0.988 \\
11. Fatigue & -0.075 & 0.670 \\
\hline
\end{tabular}

Source: Research data, 2015. Spearman correlation test. *Significant as 0.05 .

The SWAL-QOL has additional questions about needs of adjustments made by the elderly during the feeding process, as described in item methods. The results indicated that use of the feeding tube was absent in 34 subjects (97.1\%); 21 subjects, with regard to food consistency, had normal diet, including hard chewing food such as meat, bread, salad; twelve had a preference for soft foods such as cooked vegetables, soups, porridge. Regarding the consistency of the liquid, $33(94.3 \%)$ reported drink liquids such as milk, tea, juice and coffee, or liquids in general without difficulty. And two (5.7\%) mentioned fluid intake slightly or moderately thickened as vitamin.

Regardless of all interviewees have been affected by stroke, when questioned in relation to their overall health, 15 considered it good; eight, bad; eight, satisfactory; and four, as very good (Table 5).

TABLE 5. Distribution of SWAL-QOL additional questions for changes / adjustments during the swallowing process

\begin{tabular}{ccc}
\hline SWAL-QOL additional questions & & \multicolumn{2}{c}{ Elderly answers } \\
\cline { 1 - 3 } Catheter feeding & & \\
No & 34 & 97.1 \\
Yes & 1 & 2.9 \\
Total & 35 & 100.0 \\
Food consistency & & \\
Normal diet & 21 & 60.0 \\
Soft food & 12 & 34.0 \\
More doughy food & 2 & 5.7 \\
Total & 35 & 100.0 \\
Liquid consistency & & \\
General liquid & 33 & 94.3 \\
A little thicker liquid & 2 & 5.7 \\
Total & 35 & 100.0 \\
General health state & & \\
Bad & 8 & 22.9 \\
Satisfactory & 8 & 22.9 \\
Good & 15 & 42.9 \\
Very good & 4 & 11.3 \\
Excelent & 0 & 0.0 \\
Total & 35 & 100.0 \\
\hline
\end{tabular}




\section{DISCUSSION}

The SWAL-QOL is an important tool because it is considered the gold standard for determining the quality of life of patients with oropharyngeal dysphagia; it is the only questionnaire that includes the evaluation of dysphagia comprehensively, regardless the etiology, as well as monitoring the effectiveness of rehabilitation of the patient's point of view. It is also sensitive to compare the swallowing of normal individuals and dysphagia persons of different etiologies and to vary the degree of swallowing disorders. Allows to know the real impact of the changes that people experience at the time of feeding and their self-evaluation of swallowing in quality of life $\mathrm{e}^{(31,35)}$.

The elderly patients with stroke may present as a sequel oropharyngeal dysphagia, with frequent episodes of laryngeal penetration or bronchial aspiration. Studies qualitatively analyzed the oral and pharyngeal swallowing through videofluoroscopy with elderly after stroke, showing delayed onset of the pharyngeal phase, slow oral transit and laryngeal penetration are strong risk factors for sequent complications from dysphagia in this population; these data predict possible changes in other parameters such as reduction in lifting larynx, waste in pharynx and in valecule and decreased airway protection increasing the risk of aspirations, adversely affecting the quality of life of individuals by the inability to control swallowing and by laryngeal manifestations brought by the disease $\mathrm{e}^{(17,29,33)}$.

The questionnaire consists of 44 questions that have good reliability, internal consistency and reproducibility. It consists of 11 fields, and the minimum and maximum scores for each domain are zero and 100 , where $(0)$ indicates a worse quality of life versus no injury (100) both self-reported by the individual. After converting, the values of each response within each domain are added together and divided by the number of the related domain questions. For the interpretation of the results, it is considered the following classification: 0-49 severe impact, moderate impact 50-70 and 71-100 discrete impact or no impact on quality of life related to swallowing ${ }^{(20,35)}$.

The stroke refers to one of the most prevalent diseases in aging phase, therefore with the increasing number of elderly in the population, it is expected that the prevalence of this disease increases significantly ${ }^{(35)}$. In the present study, the mean age was 69.5 years, with the standard deviation of \pm 8.5 , such data have support in the literature, because stroke is the leading cause of death among people aged over 60 years and its incidence doubles every decade after that age ${ }^{(32)}$.

Regarding the variable gender, women corresponded to $54.3 \%$ of the study sample (Table 1). However, other authors have found that the stroke is more common in males, with approximately $51.43 \%{ }^{(37)}$. However, the difference between the findings is small, almost half of the samples of the studies are women. Yesilot et al. states that stroke is responsible for $14.5 \%$ of deaths in men and $15.7 \%$ of death in women, due to an average women's age higher than men's, increasing the risk factors for this disease such as increased blood pressure, high cholesterol levels and overweight ${ }^{(39)}$.

As for the level of education, it was observed that $40 \%$ of elderly patients with stroke reported having not completed the first grade of elementary school and $28.6 \%$ of this population are illiterate, these data show a lower educational level in the elderly population (Table 1). Data from the National Survey by
Household Sample (PNAD) revealed that $9.4 \%$ of individuals between 60 and 64 years are illiterate in Brazil, and in people over 65 years, this percentage rises to $29.4 \%{ }^{(30)}$.

The averages obtained by the elderly in the 11 areas investigated with the protocol ranged from severe impact (6 domains) to moderate (5 domains) on quality of life (Table 2 ). The elderly patients with stroke generally self-reported difficulties related to swallowing and/or feeding. Similarly, in another study patients with stroke were evaluated and presented changes in the quality of life in relation to swallowing that was associated with the presence of laryngotracheal aspiration, malnutrition and dislipidemia ${ }^{(27)}$.

Table 2 shows that, regarding the "Feeding time" domain that had lowest average between domains (31.8\%), which involves the questions "I take longer to eat than others" and "I take too much time to eat my meal" that can be justified by any changes resulting from concomitant aging with the consequences of stroke, such as reduced muscle strength, incoordination of chewing and swallowing, the presence of oral and pharyngeal stasis, penetrations and laryngeal aspirations. In addition, increased feeding time may be a necessary strategy to minimize such effects while feeding, Mituuti and Khaldoun Woisard and Verin found that the domain that most interfered the quality of life referred to the feeding duration ${ }^{(17,23)}$.

Regarding the comparison between genders (Table 3), there was no significant difference in the average presented in the fields, indicating that men and women had similar scores. Cassol et al. in his research showed that for the comparison between genders, men had higher average than women in sleeping areas and fatigue, in other areas men and women had similar scores ${ }^{(5)}$.

As shown in Table 4 it is clear that, with regard to the correlation between the scores in the 11 areas of SWAL-QOL protocol and age, there was a relationship between the average age and the field "Selection of food," this relationship is expressed in a negative way, that is, the higher the age, the lower the score for that domain and vice versa. Such data can be justified by changes in the masticatory capacity, correlated to the frequent appearance of periodontal disease; the total or partial maladaptive prosthesis; decreased saliva production, reducing the sensitivity of primary tastes such as sweet, bitter and acid. In addition to the factors inherent in the concomitant aging process with the consequences of stroke, there are socioeconomic, psychosocial factors associated that affect the nutritional status of the elderly. However, Pacheco observed no correlation between age and worsening in quality of life as well as Cassol et al. found no reduction in scores or worsening in quality of life in swallowing as the age of the elderly advances ${ }^{(5,6,27)}$.

Regarding the additional questions of SWAL-QOL protocol (Table 5), in respect of possible modifications/adjustments during the process of swallowing, only one patient was fed through alternative feeding pathway. Gaspar et al. aimed to evaluate the quality of life in patients with neurogenic dysphagia and during the evaluation, verified the presence of a nasogastric tube in nine patients affected by stroke, with the prerogative of the presence of dysphagia constituting one of the main causes of alternative feeding pathway use ${ }^{(10)}$. Regarding the food consistency of the elderly $60 \%$ referred to ingest foods of all consistencies, i.e., a normal diet with a variety of food items, including the most difficult foods to chew, without adjustments, and these results were also found in the study on the quality of life related to swallowing in healthy elderly ${ }^{(5)}$.

For a characterization about the consistencies, the questionnaire describes soft foods as those that are easier to chew, as for the 
most soft foods, they are processed in a blender or food processor. Steele et al. observed that there is a convention with regard to the terminology used to describe thickening levels or texture of foods, not having a global rating ${ }^{(5,36)}$.

The International Initiative of Diets in Dysphagia (IDDSI) has developed a new terminology standard and global definition consisting of a pyramid and identified eight levels to describe the modified food and liquid thickened texture used by individuals with dysphagia of all age groups, and in all cultures with regard to liquid: Extremely thin, moderately thick, midly thick, slightly thick and thin, about the food: regular, soft, minced e moist, pureed and liquidised. Such information is of paramount importance to standardization in concern to food consistencies, facilitating the management of these patients and their rehabilitation, as well as their nutrition and quality of life ${ }^{(14)}$.

In Brazil there are few studies about the quality of life using the SWAL-QOL instrument, but some inferences can be made from the results presented in this study. When comparing the values obtained for elderly patients with stroke and other populations, such as healthy elderly people, there are wide differences as the healthy population does not show such commitment during feeding, resulting in much higher average scores ${ }^{(5)}$.

Portas in his SWAL-QOL protocol validation work, averaged significantly lower scores (worse quality of life) in groups of patients with head and neck cancer, neurological vascular diseases, neurodegenerative diseases and obstructive respiratory diseases. Individuals with mild dysphagia showed an average from 50.3 to 77.1 points in SWAL-QOL in different domains. In individuals affected by stroke of the present study, the average was from 31.8 to 59.5 , confirming that proven dysphagia individuals (in varying degrees) have significantly lower avarage scores, with a negative impact on quality of life ${ }^{(31)}$.

\section{CONCLUSION}

Elderly affected by stroke presenting dysphagia have low rates on quality of life related to swallowing.

The increase in feeding time, referred to by some elderly, was the area that most interfered with quality of life due to changes from the stroke, but may also be a necessary strategy to facilitate feeding. In the field "Selection of Food", it was observed that, with age increasing, average in this area decreases resulting in a lower quality of life, it possibly refers to changes in masticatory capacity, reduced oral sensitivity, as to the socioeconomic and psychosocial factors that are conditions for food and nutritional status of the elderly.

It is noteworthy that was not performed clinical assessment by the researchers, all data were self-reported by elderly. And in this procedure, it is not enough to diagnose functional swallowing disorders, either subjectively or objectively, but add to the found data issues pertaining to quality of life, and so, contributing to a better rehabilitation of these patients. It is suggested prospective studies with larger sample sizes to better inference quality of life of this population.

\section{Authors' contributions}

Pontes ÉS: study design; data collection, performing all tecniques procedures; manuscript writing; responsible for the process of submitting the article; responsible for the translation into English and text formatting. Amaral AKFJ: study design; manuscript writing; responsible for the translation into English; text formatting; revision of the article writing. Rêgo FLC and Azevedo EHM: study design and revision of the article writing. Silva POC: statistical analysis; revision of the article writing. All authors read and approved the manuscript final version for submission.

Pontes ÉS, Amaral AKFJ, Rêgo FLC, Azevedo EHM, Silva POC. Qualidade de vida relacionada à deglutição de idosos acometidos por acidente vascular encefálico. Arq Gastroenterol. 2017,54(1):27-32.

RESUMO - Contexto - A população idosa enfrenta dificuldades diversas em consequência do processo de envelhecimento. Conceituar e avaliar sua qualidade de vida é um desafio, sendo difícil caracterizar o impacto que provoca em atividades diárias e na capacidade funcional. O acidente vascular encefálico é uma das doenças neurológicas mais incapacitantes, constituindo-se um problema de saúde pública. Como consequência agravante, tem-se a disfagia, desordem que compromete a progressão do alimento da boca ao estômago, acarretando complicações clínicas para o indivíduo. Objetivo - Caracterizar a qualidade de vida em deglutição de idosos acometidos por acidente vascular encefálico. Métodos - Estudo transversal realizado no Hospital Universitário Lauro Wanderley, em que participaram 35 idosos com acidente vascular encefálico, sendo 19 mulheres e 16 homens, com idade entre 60 e 90 anos, que autorreferiram quadro clínico geral satisfatório. Foi aplicado o protocolo Quality of Life Swallowing. Os dados foram analisados estatisticamente, por meio dos testes ANOVA, Correlação de Spearman, teste $t$, com nível de significância $P \leq 0,005$. Resultados - A idade média foi 69,5 anos; quanto aos escores obtidos pelos 35 participantes nos 11 domínios do protocolo, observou-se uma variação na pontuação média, indicando impacto grave a moderado na qualidade de vida relacionada à deglutição autorreferida (31,8\% a 59,5\%); o domínio que mais interferiu foi o de duração de alimentação $(31,8 \%)$. Conclusão - Idosos acometidos por um acidente vascular encefálico que apresente a disfagia possui escores baixos na qualidade de vida relacionada à deglutição.

DESCRITORES - Acidente vascular cerebral. Transtornos de deglutição. Saúde do idoso. Qualidade de vida.

\section{REFERENCES}

1. Amaral AKFJ. Interface da Motricidade Orofacial com a Gerontologia. In: Pernambuco, L, et al. (Orgs). Atualidades em Motricidade Orofacial. Rio de Janeiro: Revinter. 2011, p.123-133.

2. Argimon IIL. Aspectos cognitivos em idosos. Aval. Psicol. 2006;5:243-45.

3. Azevedo EHM. Ocorrência de alterações da fase faríngea em pacientes tratados do câncer de cabeça e pescoço. [Disseratation]. São Paulo: Fundação Antônio Prudente, 2012.
4. Barbosa BR, Almeida JM, Barbos MR, et al. Avaliação da capacidade funcional dos idosos e fatores associados à incapacidade. Ciência e Saúde Coletiva. 2014;19:3317-25.

5. Cassol K, Galli JFM, Zamberlan NE, et al. Qualidade de vida em deglutição em idosos saudáveis, J Soc Bras Fonoaudiol. 2012;24:223-32.

6. Catão MHCDV, Xavier AFC, Xavier AFC. O impacto das alterações do sistema estomatognático na nutrição do idoso. Rev Bras Ciên Saúde/Revista de Atenção à Saúde, 2012;9. 
7. Ciosak SI, Braz E, Costa MFBNA, et al. Senescência e senilidade: novo paradigma na Atenção Básica de Saúde. Rev Esc Enferm. 2011;45:1763-8.

8. Don kim K, Lee HJ, Lee MH, et al. Effects of neck exercises on swallowing function of patients with stroke. J Phys Ther Sci. 2015;27:1005-8.

9. Drozdz D, Mancopes R, Silva AMT, et al. Analysis of the level of dysphagia, anxiety and nutritional status before and after speech therapy in patients with stroke. Int Arch Otorhinolaryngol. 2014;18:172-7.

10. Gaspar MRF, et al. Avaliação da qualidade de vida em pacientes com disfagia neurogênica. Rev CEFAC. 2015;17:1939-45.

11. Gonçalves BFT, Bastilha GR, Costa CC, et al. Utilização de protocolos de qualidade de vida em disfagia: Revisão da literatura. Rev CEFAC. 2015;17:1333-40.

12. Gupta H, Banerjee A. Recovery of dysphagia in lateral medullary stroke. Case Rep Neurol Med. 2014;404871.

13. Gutierrez BAO, Auricchio AM, Medina NVJ. Mensuração da qualidade de vida de idosos em centros de convivência. J Health Sci Inst. 2011;29:186-90.

14. IDDSI, International Dysphagia Diet Standardization Initiative. Detailed descriptions, Testing methods and Evidence. November 8,2015.

15. Inaoka $\mathrm{C}$, Albuquerque $\mathrm{C}$. Efetividade da intervenção fonoaudiológica na progressão da alimentação via oral em pacientes com disfagia orofaríngea pós AVE Rev CEFAC. 2014;16:187-96.

16. Jacques A, Cardoso MCAF. Acidente vascular cerebral e sequelas fonoaudiológicas: atuação em área hospitalar. Rev Neurocienc. 2011;19:229-36.

17. Khaldoun E, Woisard V, Verin É. Validation in French of the SWAL-QOL scale in patients with oropharyngeal dysphagia. Gastroenterol Clin Biol. 2009;33:167-71.

18. Leow LP, Huckabee ML, Anderson T, et al. Quality of life in ageing and Parkinson's disease. Dysphagia. 2010;25:216-20.

19. Magalhães Júnior HV, Tavares JC, Magalhães AAB, et al. Caracterização da pressão da língua em idosos. Audiol Commun Res. 2014;19:375-9.

20. Mc Horney CA, Robbins J, Lomax K, et al. The SWAL-QOL and SWAL-CARE outcomes tool for oropharyngeal dysphagia in adults: III. Documentation of reability and validity. Dysphagia. 2002;17:97-114

21. Menezes DC. Impacto dos distúrbios da deglutição na qualidade de vida de parkinsonianos. Mestrado [Dissertation]. Recife; Universidade Federal de Pernambuco, Neuropsiquiatria e Ciências do comportamento. 2011:102.

22. Michou E, Mistry S, Jefferson S, et al. Characterizing the mechanismis of central and peripheral forms of neurostimulation in chronic dysphagic stroke patients Brain Stimulation. 2014;7:66-73.

23. Mituuti CT. Eficácia da eletroestimulação neuromuscular no tratamento da disfagia orofaríngea em idosos cometidos por acidente vascular encefálico. [Dissertation]. Bauru, Universidade de São Paulo. Ciências. 2015:112.

24. Nogueira SL, Ribeiro RCL, Rosado LEFPL, et al. Fatores determinantes da capacidade funcional em idosos longevos. Rev Bras Fisioter. 2010;14:322-9.
25. Nunes MCA, Jurkiewicz AL, Santos RS, et al. Correlation between brain injury and dysphagia in adult patient with stroke. Int. Arch. Otorhinolaryngol 2012;16:313-21

26. Onofri SMM, et al. Correlation between laryngeal sensitivity and penetration/ aspiration after stroke. Dysphagia. 2014;29:256-61.

27. Pacheco AC. Achados videofluoroscópicos, condição nutricional e qualidade de vida em pacientes com Acidente Vascular Encefálico. [Dissertation] Ribeirão Preto Universidade de São Paulo. Ciências. 2013:111.

28. Pansarini AC, Sassi FC, Mangilli LD, et al. Deglutição e consistências alimentares pastosas e sólidas: revisão crítica de literatura. Rev Soc Bras Fonoaudiol. 2012;17:357-62.

29. Park T, Kim Y, McCullough G. Oropharyngeal transition of the bolus in poststroke patients. Am J Phys Med Rehabil. 2013;92:320-6.

30. Pilger C, Menon MH, Mathias TAF. Características sociodemográficas e de saúde de idosos: contribuições para os serviços de saúde. Rev. Latino-AM Enfermagem. 2011:19:1-9.

31. Portas JG. Validação para a língua portuguesa-brasileira dos questionários: Qualidade de vida em disfagia (SWAL-QOL) e satisfação do paciente e Qualidade do cuidado no tratamento da disfagia (SWAL-CARE). [Dissertaton] São Paulo, Fundação Antônio Prudente, Ciências. 2009:93.

32. Rodgers H. Risk factors for first-ever stroke in older people in the North East of England: a population based study. Stroke. 2004;35:7-11

33. Santos RRD, et al. Correlation between oral and pharyngeal transit time in stroke. Audiol Commun Res. 2015;20:198-202.

34. Silva LM. Disfagia orofaríngea pós-acidente vascular encefálico no idoso. Rev. Bras. Geriatr. Gerontol. 2006;9:93-106.

35. Speyer R, Heijner BJ, Bajens LW, et al. Quality of life in oncological patients with oropharyngeal dysphagia validity and reliability of the Dutch version of the MD Anderson dysphagia inventory and the deglutition handicap index. Dysphagia. 2011;26:407-14.

36. Steele CM, Alsanei WAA, Ayanikalath S, et al. The influence of food texture and liquid consistency modification os swallowing physiology and function: a systematic review. Dysphagia. 2015;30:2-26.

37. Touzé E, Rothwell PM. Sex Differences in Heritability of Ischemic Stroke. Stroke. 2008;39:16-23.

38. Vieira DO. Validação da versão portuguesa do questionário SWAL-QOL em doentes com patologia oncológica da cabeça e pescoço. [Dissertation]. U. Porto, Oncologia Clínica. 2010:80.

39. Yesilot N, Koyuncu BA, Coban O, et al. Gender diferences in acute stroke: Istanbul medical school stroke registry Neurol India. 2011;59:174-9. 